\title{
Endogenous $\kappa$-Opioid Receptor Systems Regulate Mesoaccumbal Dopamine Dynamics and Vulnerability to Cocaine
}

\author{
Vladimir I. Chefer, ${ }^{2}$ Traci Czyzyk, ${ }^{1}$ Elizabeth A. Bolan, ${ }^{2}$ Jose Moron, ${ }^{2}$ John E. Pintar, ${ }^{1 \star}$ and Toni S. Shippenberg ${ }^{2 \star}$ \\ ${ }^{1}$ Department of Neuroscience and Cell Biology, Center for Advanced Biotechnology and Medicine, University of Medicine and Dentistry of New Jersey- \\ Robert Wood Johnson Medical School, Piscataway, New Jersey 08854, and 2Integrative Neuroscience Section, Behavioral Neurosciences Branch, National \\ Institute on Drug Abuse/Intramural Research Program, Baltimore, Maryland 21224
}

Genetic and pharmacological approaches were used to examine $\kappa$-opioid receptor (KOR-1) regulation of dopamine (DA) dynamics in the nucleus accumbens and vulnerability to cocaine. Microdialysis revealed that basal DA release and DA extraction fraction $\left(E_{\mathrm{d}}\right)$, an indirect measure of DA uptake, are enhanced in KOR-1 knock-out mice. Analysis of DA uptake revealed a decreased $K_{\mathrm{m}}$ but unchanged $V_{\text {max }}$ in knock-outs. Knock-out mice exhibited an augmented locomotor response to cocaine, which did not differ from that of wild-types administered a behavioral sensitizing cocaine treatment. The ability of cocaine to increase DA was enhanced in knock-outs, whereas c-fos induction was decreased. Although repeated cocaine administration to wild types produced behavioral sensitization, knock-outs exhibited no additional enhancement of behavior. Administration of the long-acting KOR antagonist nor-binaltorphimine to wild-type mice increased DA dynamics. However, the effects varied with the duration of KOR-1 blockade. Basal DA release was increased whereas $E_{\mathrm{d}}$ was unaltered after $1 \mathrm{~h}$ blockade. After $24 \mathrm{~h}$, release and $E_{\mathrm{d}}$ were increased. The behavioral and neurochemical effects of cocaine were enhanced at both time points.

These data demonstrate the existence of an endogenous KOR-1 system that tonically inhibits mesoaccumbal DA neurotransmission. Its loss induces neuroadaptations characteristic of "cocaine-sensitized" animals, indicating a critical role of KOR-1 in attenuating responsiveness to cocaine. The increased DA uptake after pharmacological inactivation or gene deletion highlights the plasticity of mesoaccumbal DA neurons and suggests that loss of KOR-1 and the resultant disinhibition of DA neurons trigger short- and long-term DA transporter adaptations that maintain normal DA levels, despite enhanced release.

Key words: к-opioid receptor; nucleus accumbens; dopamine; microdialysis; cocaine; nor-binaltorphimine

\section{Introduction}

The $\kappa$-opioid receptor-1 (KOR-1) and dynorphin, its endogenous ligand, are enriched in the nucleus accumbens (NAc) (Mansour et al., 1995). Systemic KOR-1 agonist administration decreases mesoaccumbal dopamine (DA) neurotransmission, and similar effects occur after selective activation of NAc KOR-1 (Spanagel et al., 1992). Although these actions were initially attributed to inhibition of DA release (Heijna et al., 1990), KOR-1 is colocalized with the dopamine transporter (DAT) in NAc DA terminals (Svingos et al., 2001). Recent studies have shown that KOR-1 agonists regulate NAc DA uptake, suggesting that KOR-1

Received Nov. 12, 2004; revised April 11, 2005; accepted April 12, 2005.

This work was supported by National Institutes of Health Grants DA-09040 (J.E.P.) and T32 MH/AG-19957 (T.C.), a New Jersey Cancer Commission Predoctoral Fellowship (T.C.), Integrative Neuroscience Initiative on Alcoholism Grant AA-01-002 (T.S.S.), and the National Institute on Drug Abuse Intramural Research Program (T.S.S., E.A.B., J.M., V.I.C.)

*J.E.P. and T.S.S. contributed equally to this work.

Correspondence should be addressed to Dr. V. I. Chefer, Integrative Neuroscience Section, Behavioral Neuroscience Branch, National Institute on Drug Abuse/Intramural Research Program, 5500 Nathan Shock Drive, Baltimore, MD 21224. E-mail:vchefer@intra.nida.nih.gov.

D01:10.1523/JNEUROSCI.0854-05.2005

Copyright $\odot 2005$ Society for Neuroscience $\quad$ 0270-6474/05/255029-09\$15.00/0 activation inhibits DA neurotransmission by two distinct mechanisms (Thompson et al., 2000).

Cocaine increases NAc DA levels by binding to DAT and inhibiting DA uptake. This increase contributes to the psychomotor stimulant and rewarding effects of cocaine. Acute KOR-1 agonist administration inhibits cocaine-induced induction of immediate early genes (IEG) (Steiner and Gerfen, 1995) and attenuates compulsive cocaine seeking (Schenk et al., 1999). Coadministration of KOR-1 agonists with cocaine attenuates the development of cocaine-induced behavioral sensitization and prevents alterations in DA neurotransmission produced by repeated cocaine administration (Heidbreder and Shippenberg, 1994; Shippenberg and Chefer, 2003). Evidence that cocaine and other psychostimulants increase preprodynorphin gene expression in the NAc and striatum has also been obtained (Daunais et al., 1993; Turchan et al., 1998). Because KOR-1 agonists inhibit DA neurotransmission, several laboratories have hypothesized that psychostimulants increase the activity of endogenous KOR-1 systems and that this increase is a homeostatic mechanism that opposes alterations in behavior and brain function resulting from repeated drug use. To date, however, a test of this hypothesis is lacking. Thus, although exogenously administered agonists at- 
tenuate various actions of cocaine, whether KOR-1 hypofunction is associated with enhanced responsiveness to cocaine is unknown.

Dialysate DA levels are increased in the NAc after acute blockade of KOR-1 receptors in this brain region (Spanagel et al., 1992). This finding suggests that endogenous KOR-1 systems regulate the basal activity of mesoaccumbal DA neurons. The mechanisms mediating this effect, however, have not been determined. Thus, conventional microdialysis techniques do not permit quantification of extracellular DA $\left(\mathrm{DA}_{\text {ext }}\right)$ levels and alterations in dialysate levels may result from changes in uptake or release. Questions also exist as to whether lack of KOR-1 signaling triggers adaptations in DA neurons that oppose increases in DA neurotransmission resulting from loss of this opioid system.

The present studies addressed these issues by examining the influence of constitutive deletion and pharmacological inactivation of KOR-1 on basal DA dynamics in the NAc and the responsiveness of mesoaccumbal DA neurons to cocaine. Microdialysis techniques and in vitro assays were used to quantify DA dynamics and cocaine-evoked DA overflow in KOR-1 knock-out (KO) and wild-type (WT) mice. Cocaine-evoked locomotion and IEG induction were also assessed. The temporal relationship between loss of KOR-1, DA dynamics, and responsiveness to cocaine was examined in studies in which the selective, long-acting $(\geq 3$ weeks) (Broadbear et al., 1994) KOR-1 antagonist norbinaltorphimine (nor-BNI) was administered to WT mice either 1 or $24 \mathrm{~h}$ before experiments.

\section{Materials and Methods}

Subjects. The KOR-1 KO mice were produced by standard techniques as described previously (Hough et al., 2000). These animals lack all KOR-1 binding activity and analgesic responses to KOR-1 agonists. The WT, heterozygous (HET), and $\mathrm{KO}$ mice used in this study were 2- to 4-month-old male siblings ( $20-30 \mathrm{~g})$, derived from the mating of HET, $\mathrm{KO}$ mice maintained on a mixed C57BL/6J $\times 129$ S6 background. Because a mixed genetic background can increase phenotypic variability of genetically modified animals, selected experiments were also performed on WT and KOR-1 KO mice after 10 generations of backcrossing of the mutant KOR-1 allele to the C57BL/6J background. Genotype was determined by Southern blotting of DNA extracted from tail samples. Male C57BL/6J mice (The Jackson Laboratory, Bar Harbor, ME) were used for pharmacological antagonism studies. All mice were maintained in a temperature- and humidity-controlled environment under a $12 \mathrm{~h}$ light/ dark cycle for at least 2 weeks before experiments. Food and water were available ad libitum. Animals were maintained in facilities accredited by the American Association for the Accreditation of Laboratory Animal Care. All experiments were conducted in accordance with the guidelines of the Institutional Care and Use Committee of the National Institute on Drug Abuse, National Institutes of Health.

Microdialysis. Mice were implanted unilaterally with a guide cannula (CMA/7; CMA/Microdialysis, Acton, MA) aimed at the NAc [anteroposterior, +1.5; mediolateral, -0.8 ; dorsoventral, -3.6 (Slotnick and Leonard, 1975)] using standard stereotaxic techniques under pentobarbital $(70 \mathrm{mg} / \mathrm{kg}$, i.p.) anesthesia. After a $5 \mathrm{~d}$ recovery period, microdialysis probes (CMA/7; membrane dimension, $0.24 \times 1 \mathrm{~mm}$ ) were manually inserted into the guide cannula $12-16 \mathrm{~h}$ before experiments, and the animals were placed in Plexiglas test chambers. The inlet tubing of the probe was connected to a microinfusion pump (model 2000 syringe pump; Instech Laboratory, Plymouth Meeting, PA) via a quartz-lined swivel (Instech Laboratory), allowing movement of the mouse in the chamber. The probes were perfused overnight with artificial CSF (aCSF) containing the following (in $\mathrm{mm}$ ): $145 \mathrm{NaCl}, 2.8 \mathrm{KCl}, 1.2 \mathrm{MgCl}_{2}, 1.2$ $\mathrm{CaCl}_{2}, 0.25$ ascorbate, and $5.4 \mathrm{D}$-glucose, $\mathrm{pH} 7.2$ (at a flow rate of 0.3 $\mu \mathrm{l} / \mathrm{min}$ ). The next day, the flow rate was increased to $0.6 \mu \mathrm{l} / \mathrm{min}$.

Control studies assessing the influence of the intra-NAc infusion of a selective KOR-1 agonist on basal dialysate DA levels were first performed to confirm the absence of KOR-mediated regulation of DA in the NAc of $\mathrm{KO}$ animals. After a $90 \mathrm{~min}$ equilibration period, five consecutive dialysis samples were collected at 10 min intervals for determination of basal DA concentrations. Probes were then perfused with aCSF containing the selective KOR agonist U-69,593 [ $(5 \alpha, 7 \alpha, 8 \beta)-(+)-N$-methyl- $N$-[7-(1pyrrolidinyl) 1-oxaspiro(4,5)dec-8-yl] benzenacetamide] (200 nM) for 20 $\mathrm{min}$, followed by normal aCSF for $50 \mathrm{~min}$. Samples were again collected at $10 \mathrm{~min}$ intervals. They were frozen in dry ice and analyzed for DA content within $24 \mathrm{~h}$ after collection.

No-net-flux microdialysis experiments, which permit quantification of basal DA dynamics (Shippenberg et al., 1999), were conducted in a separate group of animals. Four different concentrations of DA in aCSF ( $C_{\text {in }}$ of $0,5,10$, and $20 \mathrm{~nm} \mathrm{DA}$ ) were perfused through the probes in random order to determine the extracellular DA concentration $\left(\mathrm{DA}_{\text {ext }}\right)$ and extraction fraction $\left(E_{\mathrm{d}}\right)$, an indirect measure of DA uptake (Parsons et al., 1991b; Justice, 1993). After a 25 min equilibration period, two 15 min dialysis samples were collected at each $C_{\text {in }}$ concentration to quantify DA in the perfusates $\left(C_{\text {out }}\right)$ using HPLC coupled with electrochemical detection.

After the completion of no-net-flux experiments, aCSF without DA was again perfused through the probe for $40 \mathrm{~min}$ to allow equilibration of basal DA levels. Three consecutive dialysis samples were then collected to determine basal dialysate DA levels. Mice were then injected with saline $(0.1 \mathrm{ml} / 10 \mathrm{~g}$, i.p.), followed $45 \mathrm{~min}$ later by the first of three intraperitoneal injections of cocaine $(5,10$, and $15 \mathrm{mg} / \mathrm{kg}$, i.p.) with $45 \mathrm{~min}$ intervals between each injection. Samples were collected at 15 min intervals and frozen on dry ice for later quantification of DA.

The behavioral effects produced by the acute cocaine challenge were quantified during microdialysis experiments using the following behavioral rating scale. For each 5 min observational period, each animal was assigned a rating score from 1 to 8 . The definitions of each rating value were as follows: 0 , normal resting behavior (asleep or inactive, lying down, eyes open); 1, normal in place activities (e.g., grooming); 2, normal exploratory activity (slow ambulatory movements, mild sniffing, and rearing); 3 , intense sniffing with head movements; 4 , locomotion, distance more than two body lengths; 5 , stereotypy/sniffing within restricted area, bobbing, circling, licking body parts; 6 , rapid locomotion without rearing; 7 , rapid locomotion with rearing; 8 , intense stereotypy, gnawing.

For studies examining the influence of pharmacological antagonism of KOR-1 on basal DA dynamics, C57BL/6J mice received a subcutaneous injection of the selective KOR-1 antagonist nor-BNI $(10 \mathrm{mg} / \mathrm{kg})$ or an equivalent volume of saline. Previous studies (Broadbear et al., 1994) have shown that this dose results in the selective and long-lasting $(\geq 3$ week) blockade of KOR-1. No-net-flux experiments (as described above) commenced 1 and $24 \mathrm{~h}$ after nor-BNI injection, and separate animals were used at each time point. The influence of nor-BNI treatment on cocaine-evoked dialysis DA levels was determined in additional groups of $\mathrm{C} 57 \mathrm{BL} / 6 \mathrm{~J}$ mice that had received nor-BNI or saline $24 \mathrm{~h}$ before microdialysis studies. After the equilibration period, six consecutive dialysis samples were collected at $10 \mathrm{~min}$ intervals for determination of basal DA concentrations. Animals then were injected with saline $(0.1 \mathrm{ml} / 10 \mathrm{~g}$, i.p.), followed $60 \mathrm{~min}$ later by an intraperitoneal injection of $15 \mathrm{mg} / \mathrm{kg}$ cocaine. Samples were collected at $10 \mathrm{~min}$ intervals for $90 \mathrm{~min}$. The behavioral effects produced by the acute challenge doses of cocaine were measured during these microdialysis experiments using a Tru Scan activity monitoring system (Coulbourn Instruments, Allentown, PA) designed for use in the mouse. Each station had an on-board microprocessor to process beam breaks and prepare coordinate data for downloading on the computer for filing and processing.

Chromatographic analysis of brain microdialysates. The separation and quantification of DA was achieved by HPLC coupled to electrochemical detection using a microbore HPLC column $(100 \times 2 \mathrm{~mm}, \mathrm{C}-18,3 \mu \mathrm{M}$, MF-8957; Bioanalytical Systems, West Lafayette, IN) and a BAS LC-4C amperometric detector (Bioanalytical Systems). The applied potential was set at $700 \mathrm{mV}$ versus $\mathrm{Ag} / \mathrm{AgCl}$ reference electrode. The mobile phase consisted of $0.15 \mathrm{M} \mathrm{NaH}_{2} \mathrm{PO}_{4}, 1.7 \mathrm{~mm}$ sodium octyl sulfate, $1.0 \mathrm{~mm}$ EDTA, and 12\% methanol, pH 5.0. All reagents were analytical grade and were obtained from Sigma (St. Louis, MO) and Fluka (Ronkonkoma, 
NY). The mobile phase was filtered through a $0.22 \mu \mathrm{m}$ filter (Millipore, Bedford, MA) and degassed with helium for $20 \mathrm{~min}$. Samples were analyzed at a flow rate of $0.5 \mathrm{ml} / \mathrm{min}$ and a column pressure of $\sim 3000 \mathrm{psi}$. The elution time of DA was $\sim 3 \mathrm{~min}$, and the limit of detection for DA was $0.3-0.5 \mathrm{~nm}$.

Histology. After the completion of experiments, animals were deeply anesthetized with pentobarbital and killed by decapitation. The brains were removed and frozen. Histological verification of the site of probe placement was obtained via coronal sections ( $20 \mu \mathrm{m}$ thick) using a microtome (model 5030; Hacker Instruments, Fairfield, NJ). Only data obtained from animals with histologically correct placements were used for subsequent statistical analysis.

Measurement of $\left[{ }^{3} \mathrm{H}\right] \mathrm{DA}$ uptake in synaptosomes. KO mice and their WT littermates were killed by decapitation, and their brains were removed to an ice-cooled dish for dissection of the NAc. Because the amount of tissue from NAc of one mouse was insufficient for the analysis, tissue from 8-10 mice was pooled. Dissected tissue was placed in ice-cold Krebs'-Ringer's buffer (in mm: $125 \mathrm{NaCl}, 1.2 \mathrm{KCl}, 1.2 \mathrm{MgSO}_{4}, 1.2 \mathrm{CaCl}_{2}$, $22 \mathrm{NaHCO}_{3}, 1 \mathrm{NaH}_{2} \mathrm{PO}_{4}$, and 10 glucose, adjusted to $\mathrm{pH}$ 7.4) containing $0.32 \mathrm{~m}$ sucrose and homogenized using a glass homogenizing tube and a Teflon pestle. After centrifugation at $1000 \times g$ for $10 \mathrm{~min}$ at $4^{\circ} \mathrm{C}$, the pellet was discarded, and the resultant supernatant was centrifuged for 15 min at $16,000 \times g$. The resulting P2 pellet remained on ice until it was resuspended for the uptake assay. The assay was performed in Krebs'Ringer's buffer containing $0.64 \mathrm{~mm}$ ascorbic acid and $0.8 \mathrm{~mm}$ pargyline. Saturation analysis was performed with $\left[{ }^{3} \mathrm{H}\right] \mathrm{DA}$ concentrations ranging from 0.025 to $1.2 \mu \mathrm{M}$. The uptake assay was initiated by the addition of aliquots of the synaptosomal fraction. Tubes were incubated for $4 \mathrm{~min}$ at $37^{\circ} \mathrm{C}$. Blanks consisted of samples incubated at $4^{\circ} \mathrm{C}$. The assay was terminated by placing the tubes on ice and adding $5 \mathrm{ml}$ of ice-cold Krebs'Ringer's buffer. The solutions were then filtered through Whatman (Clifton, NJ) glass microfiber filters (GF/C), which were presoaked in $0.1 \%$ polyethyleneimine to reduce nonspecific binding using a Brandel (Gaithersburg, MD) cell harvester. After filtration, the filters were washed twice with $5 \mathrm{ml}$ of ice-cold Krebs'-Ringer's buffer and placed in scintillation vials, $3 \mathrm{ml}$ of Bio-Safe II scintillation fluid (Research Products, Mount Prospect, IL) was added to each tube, and radioactivity was determined by liquid scintillation spectrometry.

Western blot analysis of DAT protein. Dissected NAc from KOR-1 knock-out mice and wild-type littermates were homogenized in lysis buffer (50 mm Tris-HCl, pH 8.0, 150 mm sodium chloride, 1.0\% Igepal CA- $630,0.5 \%$ sodium deoxycholate, and $0.1 \%$ SDS) containing protease inhibitors [20 $\mu \mathrm{M} 4$-(2-aminoethyl)-benzenesulfonyl fluoride, $10 \mu \mathrm{M}$ EDTA, 13 nм bestatin, $140 \mathrm{~nm}$ E-64, $10 \mu \mathrm{m}$ leupeptin, and $3 \mathrm{~nm}$ aprotinin] and centrifuged at $14,000 \times g$ for $20 \mathrm{~min}$ at $4^{\circ} \mathrm{C}$. The protein concentration of each sample was measured using a commercial protein assay kit (Bio-Rad, Hercules, CA). Equal amounts of protein were separated on $10 \%$ polyacrylamide gels and transferred to polyvinylidene difluoride membranes. DAT levels were determined using a monoclonal antibody raised against the $\mathrm{N}$ terminus of the DAT (1:5000; Chemicon, Temecula, CA). Detection was performed by enhanced chemiluminescence (Amersham Biosciences, Piscataway, NJ) with a horseradish peroxidase-conjugated secondary antibody (1:5000; Upstate Biotechnology, Lake Placid, NY). Actin levels were determined using a monoclonal antibody recognizing an $\mathrm{N}$-terminal epitope of the $\mu$-isoform of actin (1:4000; Sigma) to control for differences in protein loading. For quantification, films were scanned at high resolution using an HP Scanjet 7400c (Hewlett-Packard, Palo Alto, CA), and band densities were determined using NIH ImageJ image analysis software. The relative density of the bands obtained for DAT were normalized against those of $\beta$-actin and were analyzed by unpaired $t$ tests with Welch's correction using the Prism 4.0 statistical software package (GraphPad Software, San Diego, CA). The significance level for all analyses was $p \leq 0.05$.

Influence of KOR-1 deletion on cocaine-evoked IEG induction. RNase protection assays (RPAs) were used to quantify basal and cocaine-evoked induction of c-jun, jun B, jun D, c-fos, fos B, fra- 1 , and fra-2 in whole brain of KO mice and their WT littermates. Mice received an intraperitoneal injection of either saline $(0.1 \mathrm{ml} / 10 \mathrm{~g}$, i.p.) or $20 \mathrm{mg} / \mathrm{kg}$ cocaine. Thirty minutes later, mice were killed, and total RNA was extracted from whole brain using a standard acid phenol extraction method. Levels of IEG RNAs were determined using a multiprobe RPA system (Riboquant; PharMingen, San Diego, CA). Probes were transcribed using $\left[{ }^{32} \mathrm{P}\right] \mathrm{UTP}$ (mouse Fos/Jun template set) and hybridized overnight to $20 \mu \mathrm{g}$ of total RNA at $56^{\circ} \mathrm{C}$. After RNase and proteinase $\mathrm{K}$ treatments and phenolchloroform extraction, protected fragments were resolved on a $5 \%$ acrylamide sequencing gel with undigested probe used as a size marker. Bands were visualized by both autoradiography and phosphoimaging. The volume density for each band was analyzed using the Image Quant program. All data were normalized to the mRNA levels of two housekeeping genes, ribosomal protein L32 (Rpl32) and GAPDH (glyceraldehyde-3-phosphate dehydrogenase), by multiplying the band volume density in a given lane by the weighted average of Rpl32 and GAPDH band volume densities.

Behavioral sensitization to cocaine in KOR KO and WT animals. To determine whether KOR-1 deletion affects the development of behavioral sensitization to cocaine, WT and $\mathrm{KO}$ mice maintained on a C57BL/6J background received once daily injections of saline $(0.1 \mathrm{ml} / 10$ g), followed $60 \mathrm{~min}$ later by an injection of cocaine ( $15 \mathrm{mg} / \mathrm{kg}$, i.p.) for $5 \mathrm{~d}$. Locomotor activity was monitored after each injection. Three days after the cessation of the repeated treatment regimen, locomotor activity in response to saline and cocaine was determined. Locomotor activity was measured using a Tru Scan activity monitoring system (Coulbourn Instruments) designed for use in the mouse. Each station had an onboard microprocessor to process beam breaks and prepare coordinate data for downloading on the computer for filing and processing.

Reagents. Cocaine hydrochloride, U-69,593, and nor-BNI were supplied by the Research Technology Branch of the National Institute on Drug Abuse (Rockville, MD) and prepared in sterile saline. The volume of all injections was $0.1 \mathrm{ml} / 10 \mathrm{~g}$. U-69,593 perfused through the microdialysis probe $(200 \mathrm{~nm})$ was dissolved in aCSF. $\left[{ }^{3} \mathrm{H}\right] \mathrm{DA}$ (specific activity, $50 \mathrm{Ci} / \mathrm{mmol}$ ) was obtained from Amersham Biosciences.

Data analysis. Microdialysis data are expressed in nanomolar. $\mathrm{DA}_{\mathrm{ext}}$ and $E_{\mathrm{d}}$ were determined for each animal by plotting the net change in DA $\left(C_{\text {in }}-C_{\text {out }}\right)$ against $C_{\text {in }}$. DA $A_{\text {ext }}$ and $E_{\mathrm{d}}$ levels were assessed using linear regression (Parsons et al., 1991a,b). The point when no DA was gained or lost $\left(C_{\text {in }}-C_{\text {out }}=0\right)$ represents an unbiased estimate of $\mathrm{DA}_{\text {ext }}$. The slope of the linear regression line represents the $E_{\mathrm{d}}$, an indirect measure of DA uptake (Smith and Justice, 1994).

Cocaine-evoked dialysate DA levels, behavioral rating score data, as well as locomotor activity data were converted to area under the curve (AUC) values using a standard trapezoid method (Gibaldi and Perier, 1975). The resultant data as well as the average values for $\mathrm{DA}_{\text {ext }}$ and $E_{\mathrm{d}}$ were subjected to one- or two-way ANOVA. Post hoc simple main effect analyses and pairwise comparisons were performed when the initial $p$ value was significant. The average basal dialysate DA concentrations in experiments in which U-69,593 was perfused through the microdialysis probe were subjected to an unpaired $t$ test with Welch's correction. DA uptake data were subjected to unpaired $t$ test with Welch's correction. For each IEG, a two-way ANOVA was performed with additional unpaired $t$ tests done to compare all groups. The accepted value of significance for all tests was $p \leq 0.05$. The data are presented as mean \pm SEM.

\section{Results}

\section{Steady-state DA dynamics}

Pharmacological studies indicate that the tonic activation of KOR-1 by its endogenous ligand inhibits the basal activity of mesoaccumbal DA neurons. We therefore asked whether the basal dynamics of DA neurotransmission were altered in the NAc of KOR-1 mice. Control experiments assessing the influence of the selective KOR-1 agonist U-69,593 on dialysate DA levels in the NAc confirmed the lack of KOR-mediated regulation of DA in $\mathrm{KO}$ mice. Consistent with previous studies in the rat, infusion of the selective KOR-1 agonist U-69,593 into the NAc of WT mice significantly decreased dialysate DA concentrations in the NAc to $32.8 \pm 4.9 \%$ of basal values. In contrast, infusion of U-69,593 to mutant mice failed to affect DA levels. Analysis of AUC values for U-69,593-induced DA levels revealed a significant effect of drug $\left(F_{(1,7)}=23.36 ; p=0.02\right)$ and genotype $\left(F_{(1,7)}=6.07 ; p=0.04\right)$, 

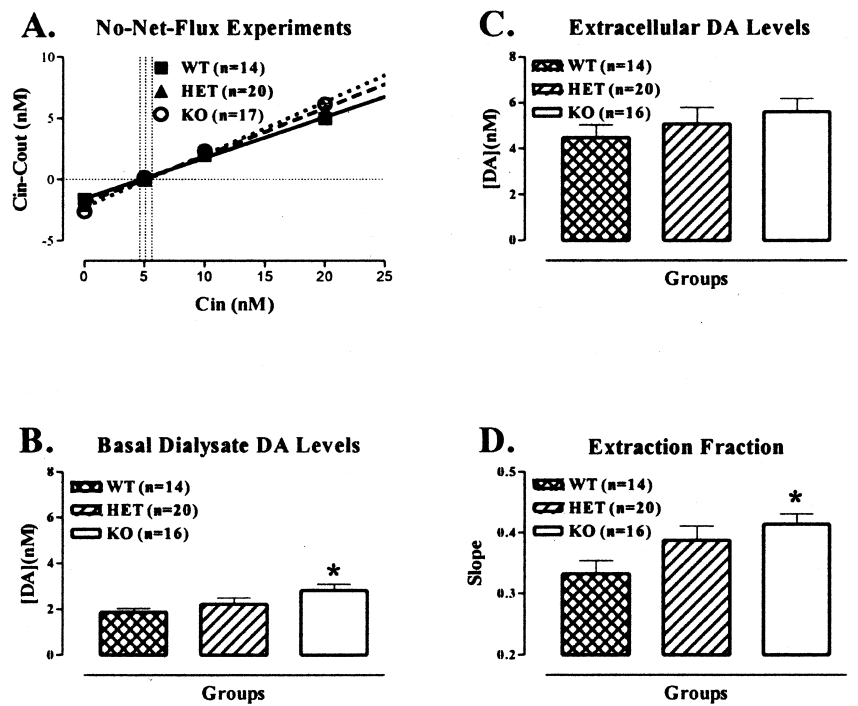

Figure 1. Basal DA dynamics in the NAc of WT, HET, and KOR-1 KO mice. A, Plot of the average gain or loss of $D A\left(C_{\text {in }}-C_{\text {out }}\right)$ to or from perfusate and the average linear regression fit of the data from no-net-flux microdialysis for each experimental group. The slope of the regression line represents the $E_{\mathrm{d}}$. The point when no DA is gained or lost from the perfusate $\left(C_{\mathrm{in}}\right.$ $C_{\text {out }}=0$ ) represents an unbiased estimate of $D A_{\text {ext }}$ concentration. The dotted line represents the average regression line for $\mathrm{KO}$ mice and has a significantly greater slope relative to WT controls (solid line). $\boldsymbol{B}$, Bar graph of basal dialysate levels (nanomolar) expressed as means \pm $\mathrm{SEM} ; n$ indicates number of animals per experimental group. * indicates significant difference in dialysate DA levels between WT and K0 animals (Newman-Keuls multiple comparison test). $\boldsymbol{C}$ Bar graph of basal $D A_{\text {ext }}$ (nanomolar) expressed as means $\pm S E M$. ANOVA revealed no significant difference in this parameter between genotypes $\left(F_{(2,47)}=0.83 ; p=0.44\right)$. $D$, Bar graph of $E_{\mathrm{d}}$ expressed as the mean $\pm \mathrm{SEM}$. ${ }^{*}$ denotes significant difference in $E_{\mathrm{d}}$ (Newman-Keuls multiple comparison test).

as well as a significant drug $\times$ genotype interaction $\left(F_{(1,7)}=7.34\right.$; $p=0.03)$. Analysis of simple effects showed that there was a significant effect of the drug in WT $\left(F_{(1,4)}=27.35 ; p=0.006\right)$ but not in $\mathrm{KO}\left(F_{(1,3)}=2.63 ; p=0.204\right)$ mice.

Importantly, analysis of basal dialysate levels in these experiments revealed marked differences between genotypes. The basal dialysate concentration in $\mathrm{KO}$ mice $(5.3 \pm 1.0 \mathrm{nM})$ was significantly higher $(p=0.05 ; t=1.97 ; \mathrm{df}=1,5)$ than that of WT mice $(3.3 \pm 0.7 \mathrm{nM})$ (data not shown). A similar increase (1.5-fold) in basal dialysate DA levels was also observed in KOR-1 KO mice maintained on a pure C57BL/6J background, indicating that the effects of gene deletion were not a function of background strain.

To examine the mechanism underlying the elevation of basal dialysate DA levels in $\mathrm{KO}$ mice, quantitative no-net-flux microdialysis was used in an additional group of animals to quantify $\mathrm{DA}_{\text {ext }}$ and $E_{\mathrm{d}}$ (Fig. $1 A-C$ ). These studies confirmed that basal dialysate DA levels in the NAc were significantly higher in $\mathrm{KO}$ mice compared with WT controls (Fig. $1 B$ ) (ANOVA, $F_{(2,49)}=$ 3.35; $p<0.05$; Newman-Keuls multiple comparison test, $p<$ $0.05)$. Dialysate DA levels in HET mice were intermediate to WT and $\mathrm{KO}$ mice, indicating a gene-dose relationship. No-net-flux (Fig. 1A) revealed no significant difference in basal $\mathrm{DA}_{\text {ext }}$ between genotypes (ANOVA, $F_{(2,47)}=0.83 ; p=0.44$ ) (Fig. $1 C$ ). However, the $E_{\mathrm{d}}$ of $\mathrm{DA}$, an indirect measure of the rate of DA uptake in this brain region (Smith and Justice, 1994), was greater in KOR-1 KO mice (ANOVA, $F_{(2.47)}=3.49$; $p<0.05$; NewmanKeuls multiple comparison test, $p<0.05$ ) (Fig. 1D), suggesting that DA uptake is increased in KOR-1 KO mice. As with dialysate DA levels, the $E_{\mathrm{d}}$ in HET mice was intermediate to WT and $\mathrm{KO}$ mice. Because $\mathrm{DA}_{\text {ext }}$ is determined by release and reuptake, the
Table 1. Kinetic parameters of $\left[{ }^{3} \mathrm{H}\right] \mathrm{DA}$ uptake in the NAc synaptosomes from KO and WT animals

\begin{tabular}{lll}
\hline & $V_{\max }\left(\mathrm{pmol} \cdot \mathrm{min}^{-1} \cdot \mathrm{mg}^{-1}\right)$ & $K_{\mathrm{m}}(\mu \mathrm{m})$ \\
\hline WT & $19.10 \pm 0.45$ & $0.41 \pm 0.02$ \\
K0 & $17.84 \pm 0.24$ & $0.24 \pm 0.01$ \\
\hline
\end{tabular}

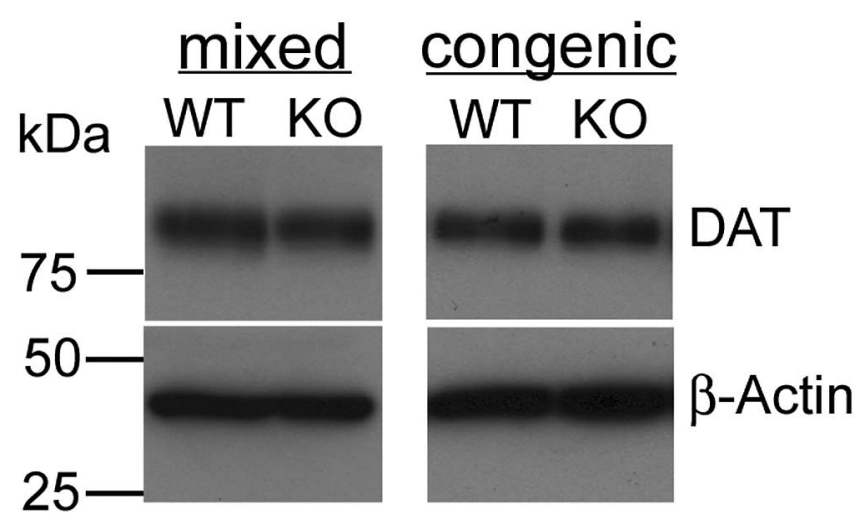

Figure 2. Unaltered levels of DAT in KOR-1 KO mice of mixed (C57BL/6J $\times 12956)$ and congenic (C57BL/6J) backgrounds are shown by Western blot analysis. For quantification, the intensity of each DAT band was normalized to the $\beta$-actin band for each lane. The mean relative density and SEM were calculated for each pair. Comparisons between genotypes were made using an unpaired $t$ test with Welch's correction. For mixed background, the mean relative density for WT is $0.73 \pm 0.21$ versus a mean of $0.76 \pm 0.07$ for KO ( $p=0.914$ ). For the congenic background, WT has a mean of $0.65 \pm 0.02$ versus $K 0$ with a mean of $0.79 \pm 0.13$ $(p=0.468)$. No statistically significant differences were seen. The immunoblots are representative comparisons.

findings that the DA uptake is greater in KOR-1 KO mice compared with WT controls whereas $\mathrm{DA}_{\text {ext }}$ is unchanged indicates that DA release is increased in KOR-1 KO. Therefore, although the apparent presynaptic inhibitory control of DA release through KOR-1 is absent in KO mice (see Discussion) and leads to increased DA release in the NAc, this increase is counterbalanced by a compensatory increase in DA uptake. As a consequence of this compensation, $\mathrm{DA}_{\mathrm{ext}}$ is unchanged.

To confirm this finding, the kinetics of $\left[{ }^{3} \mathrm{H}\right] \mathrm{DA}$ uptake was determined in synaptosomes prepared from the NAc of $\mathrm{KO}$ and WT mice. Saturation analysis revealed no effect of genotype on the $V_{\max }$ of [ ${ }^{3} \mathrm{H}$ ]DA uptake (Table 1). However, KOR-1 deletion produced a twofold decrease in $K_{\mathrm{m}}$, indicating an increased affinity of DA uptake in the NAc of mutant mice.

To determine the relative amounts of DAT in the NAc of wild-type and KOR-1 knock-out mice, Western blots using a DAT monoclonal antibody were performed (Fig. 2). Values of DAT protein were normalized to the levels of $\beta$-actin immunoreactivity to control for equal protein loading. DAT expression in the NAc did not differ between WT and $\mathrm{KO}$ mice maintained on the mixed background ( $p=0.914 ; n=3$ per genotype). Similarly, no difference in the congenic animals was seen.

Influence of KOR-1 deletion during cocaine-evoked dialysate DA levels and locomotion

The systemic administration of cocaine in an escalating dose paradigm significantly increased dialysate DA levels in the three genotypes compared with that produced by saline injections (Fig. 3 ). Analysis of area under the curve values (Fig. $3 B$ ) revealed significant main effects of cocaine dose $\left(F_{(2,49)}=107.76 ; p<\right.$ $0.01)$ and genotype $\left(F_{(2,49)}=3.19 ; p=0.05\right)$ but no dose by genotype interaction $\left(F_{(2,49)}=1.49 ; p=0.12\right)$, indicating that 
A.

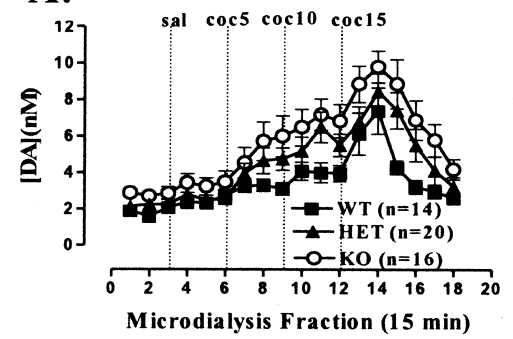

B.

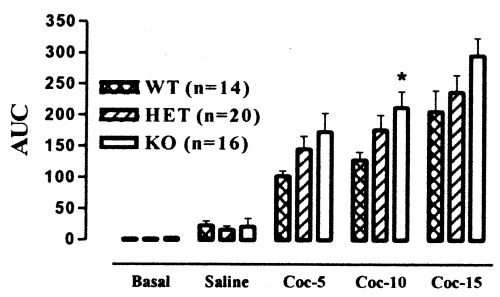

C.

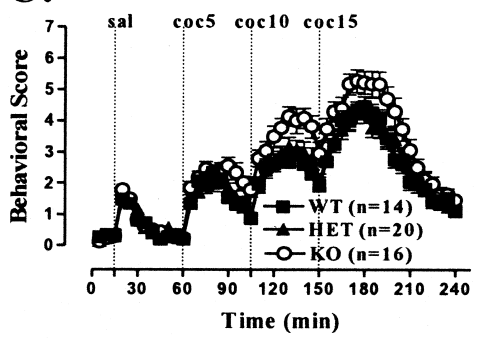

D.

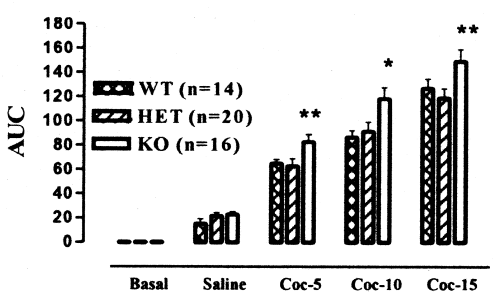

Figure 3. Basal and cocaine-induced locomotor activity and DA levels in the NAc in WT, HET, and KOR-1 KO mice. $\boldsymbol{A}$, Time course of dialysate DA levels in the NAc in WT (filled squares), HET (filled triangles), and KOR-1 KO (open circles) mice. Each point represents the mean \pm SEM; $n$ indicates the number of animals per experimental group. Abscissa, Microdialysis fractions (15 min) before and after cocaine injections. Vertical dotted lines correspond to the time of saline (sal) and cocaine (coc) $(5,10$, and 15 $\mathrm{mg} / \mathrm{kg}$ ) injections. $\boldsymbol{B}, \mathrm{AUC}$ values for cocaine-evoked DA levels expressed as means \pm SEM. * denotes significant difference between WT and KO mice. $C$, The time course of locomotor activity before and after cocaine challenge in WT (filled squares), HET (filled triangles), and KOR-1 KO (open circles) mice. Each point represents the mean \pm SEM; $n$ indicates the number of animals per experimental group. Abscissa, Time (minutes). Vertical dotted lines represent the time of saline and cocaine (5, 10, and $15 \mathrm{mg} / \mathrm{kg}$ ) injections. D, AUC values for cocaine-evoked locomotor expressed as means $\pm S E M$. * denotes significant difference between WT and $\mathrm{KO}$ mice. ${ }^{* *}$ denotes significant difference between $\mathrm{HET}$ and $\mathrm{KO}$ mice.

cocaine produced a significant dose-related increase in DA in all animals. However, the magnitude of the increase was genotype dependent. Consistent with the results of microdialysis studies, a significant difference between genotypes in the locomotor activating effects of cocaine was seen. Analysis of AUC values for cocaine-induced locomotion revealed significant effects of cocaine $\left(F_{(2,49)}=230.9 ; p<0.01\right)$ and genotype $\left(F_{(2,49)}=7.43 ; p<\right.$ $0.01)$, as well as a significant cocaine $\times$ genotype interaction $\left(F_{(2,49)}=2.43 ; p=0.046\right)$. Cocaine increased locomotor activity in all animals, but KO mice exhibited an enhanced response compared with WT controls. Post hoc tests (Scheffé's multiple comparison tests) revealed significant differences between WT controls and $\mathrm{KO}$ mice after $10 \mathrm{mg} / \mathrm{kg}$ cocaine $(p=0.01)$ and between HET and KO mice after 5 and $15 \mathrm{mg} / \mathrm{kg}$ cocaine $(p<0.05)$ (Fig. $3 C, D)$. There were no differences in spontaneous locomotor activity between genotypes or in the response to saline injection $(p>0.05)$.

\section{Influence of KOR-1 deletion on cocaine-induced \\ IEG expression}

In view of the increase in cocaine-evoked dialysate DA levels and cocaine-induced locomotor activity in $\mathrm{KO}$ mice, we next compared the responses of WT and KO mice to acute cocaine treatment at the molecular level. RPAs allowed for the simultaneous characterization of the mRNA expression levels of seven IEGs: c-jun, jun B, jun D, c-fos, fos B, fra-1, and fra-2. No differences between genotypes in basal levels of $\mathrm{c}$-fos (Fig. $4 A$ ) or the other IEGs were seen. However, all IEGs except c-jun and jun D were significantly increased relative to basal levels after acute cocaine administration. A two-way ANOVA for c-fos (Fig. 4) showed a significant effect of genotype $\left(F_{(1,11)}=4.8\right.$; $p=0.05)$ and drug treatment $\left(F_{(1,11)}=\right.$ 43.6; $p<0.0001)$, as well as a significant interaction between genotype and treatment $\left(F_{(1,11)}=5.4 ; p=0.04\right)$. Post hoc tests revealed a significant effect of drug treatment, indicating that $\mathrm{KO}$ mice showed a significantly lower induction of $\mathrm{c}$-fos (30\%) compared with WT mice $(48 \%)$ $(p<0.001$ ) (Fig. $4 A, B$ ). For jun $\mathrm{B}$, there was a significant effect of drug treatment $\left(F_{(1,11)}=18.9 ; p=0.001\right)$ and a significant interaction between genotype and drug treatment $\left(F_{(1,11)}=5.52 ; p=0.04\right)$. Post hoc tests revealed significant induction of jun B $(60 \% ; p=0.002)$ in WT but not in KO $(26 \% ; p>0.1)$ mice. For fos $\mathrm{B}$, there was a significant effect of genotype $\left(F_{(1,11)}\right.$ $=8.3 ; p=0.01)$ and drug treatment $\left(F_{(1,11)}=6.6 ; p=0.03\right)$ but no significant interaction. Cocaine increased fos $\mathrm{B}$ induction by $30 \%$ in WT animals and by only $11 \%$ in $\mathrm{KO}$ mice. The decreased induction of these IEGs in KO mice is similar to that typically seen in the NAc of WT mice after repeated intermittent injections of cocaine (Hope et al., 1992; Zhang et al., 2002).

Influence of KOR-1 deletion on cocaineinduced behavioral sensitization

To determine whether the behavioral response to repeated injections of cocaine differ as a function of genotype, sensitization to the locomotor activating effects of cocaine was assessed in WT and KO mice that received once daily injections of saline or cocaine for $5 \mathrm{~d}$. Locomotor activity was quantified on treatment days 1, 3, and 5 and $3 \mathrm{~d}$ after the cessation of the repeated cocaine treatment regimen (Fig. 5). ANOVA revealed a significant effect of daily injections (treatment) on locomotor activity $\left(F_{(1,16)}=8.58\right.$; $\left.p<0.01\right)$ in both genotypes, as well as a significant treatment $\times$ genotype interaction $\left(F_{(1,16)}=3.49 ; p=0.02\right)$. Analysis of simple effects revealed a significant effect of daily treatment on locomotor activity in WT $\left(F_{(1,7)}=10.59 ; p<0.01\right)$ but not in $\mathrm{KO}\left(F_{(1,9)}=\right.$ $1.42 ; p=0.26)$ mice. These results indicate that, although WT animals exhibit a progressive increase in the locomotor response to a cocaine challenge after repeated injections of cocaine (e.g., sensitization), sensitization fails to develop in $\mathrm{KO}$ animals. Importantly, there was a significant difference between genotypes in cocaine-induced locomotion on the first $\left(F_{(1,17)}=4.38 ; p=0.05\right)$ but not on the last $\left(F_{(1,17)}=0.57 ; p=0.46\right)$ day of treatment, suggesting that the response of $\mathrm{KO}$ mice to acute cocaine is equal in magnitude to that of WT mice that had received a behaviorally sensitizing cocaine treatment regimen.

\section{Influence of acute blockade of KOR-1 on basal DA dynamics in $\mathrm{C} 57 \mathrm{BL} / 6 \mathrm{~J}$ mice}

To determine whether similar changes in DA neurotransmission occur in response to acute or prolonged KOR-1 inactivation, C57BL/6J were pretreated with the selective KOR-1 antagonist nor-BNI. Previous studies (Broadbear et al., 1994) have shown that a single injection of this antagonist results in a selective and long-lasting ( $\geq 3$ weeks) blockade of KOR-1 receptors. Basal DA 


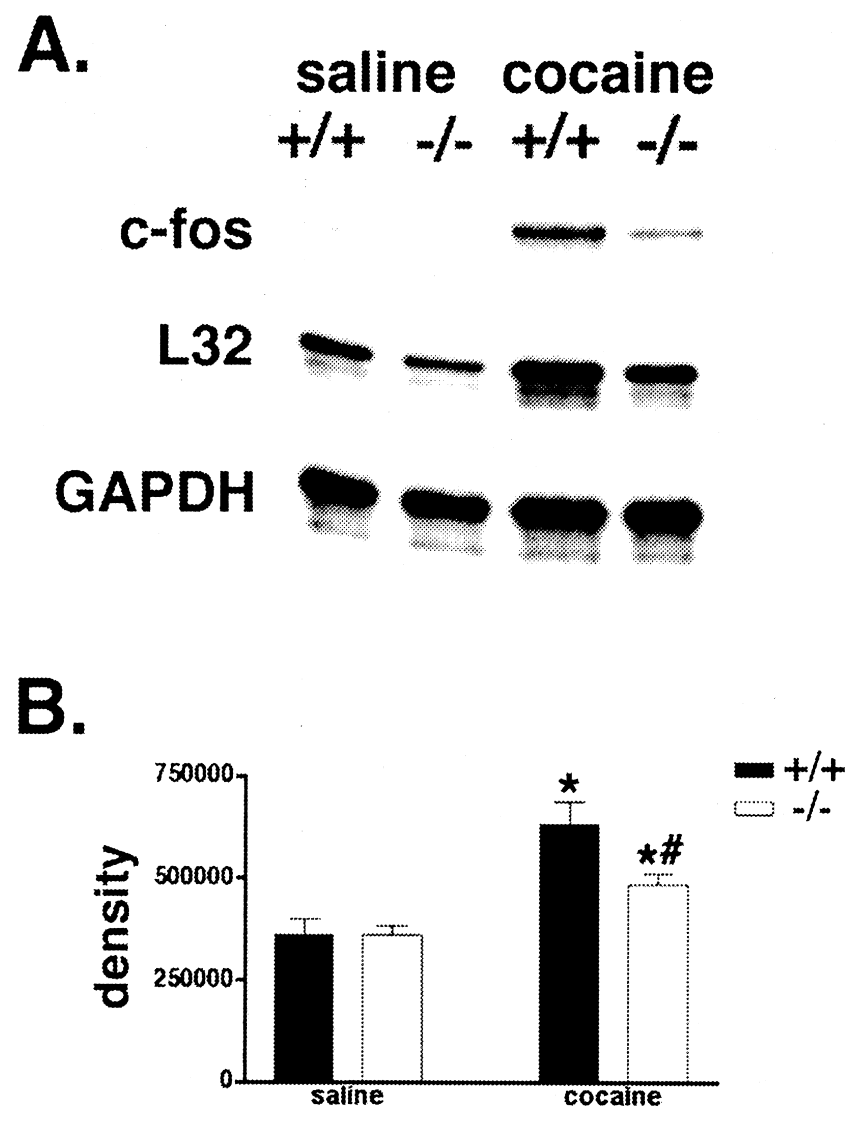

Figure 4. Induction of IEGs after acute cocaine challenge in WT and KOR-1 KO mice. $A, A$ representative RPA gel shows protected fragments from WT and KOR-1 KO mice after acute injection of saline or cocaine $(20 \mathrm{mg} / \mathrm{kg})$. The housekeeping genes $\mathrm{L} 32$ and GAPDH were used to quantitate levels of RNA per lane. Quantitative decreases in induction of $c-$ fos were observed in KOR-1 KO animals after this dose of cocaine. $B$, c-fos is significantly increased in both WT and KOR-1 KO mice after cocaine injection, but the induction is significantly less robust in KOR-1 KO mice. * denotes significant difference between saline- and cocaine-treated animals; \# denotes significant difference between WT (filled bars) and K0 (open bars) mice.

dynamics and cocaine-induced levels of DA in the NAc were assessed 1 and $24 \mathrm{~h}$ after nor-BNI injection in separate groups of mice. The effects of nor-BNI on basal DA dynamics differed as a function of the duration of KOR-1 blockade. Basal DA $\mathrm{ext}_{\text {t }}$ was significantly elevated $1 \mathrm{~h}$ after nor-BNI injection $(p=0.037 ; t=$ $2.25 ; \mathrm{df}=17)($ Fig. $6 A)$. However, the $E_{\mathrm{d}}$ was unaltered at this time point $(p=0.99 ; t=0.006 ; \mathrm{df}=15)$, suggesting that the increase in $\mathrm{DA}_{\text {ext }}$ results from an increase in release. Twenty-four hours after nor-BNI administration, however, $\mathrm{DA}_{\mathrm{ext}}$ had returned to control values ( $p=0.7 ; t=0.36$; $\mathrm{df}=11$ ) whereas the $E_{\mathrm{d}}$ was significantly increased relative to that of saline-treated animals $(p=0.039 ; t=2.25 ; \mathrm{df}=16)$ (Fig. $6 B)$, suggesting that basal DA uptake and release are elevated at this later time point. There was no difference in DAT protein in the NAc between control and nor-BNI-treated animals at either time point (data not shown).

Influence of acute blockade of KOR-1 on cocaine-evoked DA levels and behavior

The influence of pharmacological blockade of KOR-1 on cocaine-evoked dialysate DA levels and locomotion is shown in Figure 7. ANOVA conducted for dialysis DA levels revealed a significant effect of cocaine challenge (saline vs cocaine; $F_{(1,52)}=$ 101.04; $p<0.001$ ), no effect of pretreatment (vehicle vs nor-BNI;
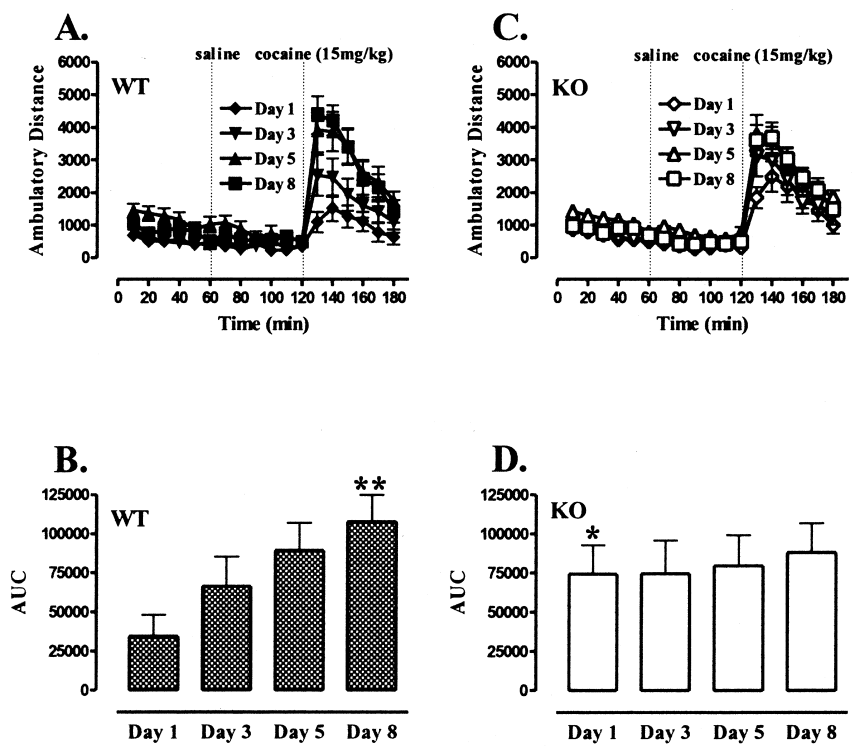

Figure 5. Development of cocaine-induced behavioral sensitization in WT but not KOR-1 KO mice. $\boldsymbol{A}, \boldsymbol{C}$, Time course of locomotor activity in WT $(\boldsymbol{A})$ and $\mathrm{KO}(\boldsymbol{C})$ animals $(\mathrm{C} 57 \mathrm{BL} / 6 \mathrm{~J}$ background) before and after intraperitoneal injections of saline $(0.1 \mathrm{ml} / 10 \mathrm{~g})$ and cocaine (15 $\mathrm{mg} / \mathrm{kg}$ ) on different treatment days. Each point represents the mean \pm SEM. Ordinate, Ambulatory distance. Abscissa, Time (minutes). Vertical dotted lines represent the time of saline and cocaine injections. $\boldsymbol{B}, \boldsymbol{D}, \mathrm{AUC}$ values for cocaine-evoked locomotor activity response expressed as means \pm SEM. ${ }^{*}$ denotes significant difference between WT and KO mice. ${ }^{* *}$ denotes significant difference between the first and the last day of treatment in WT mice.
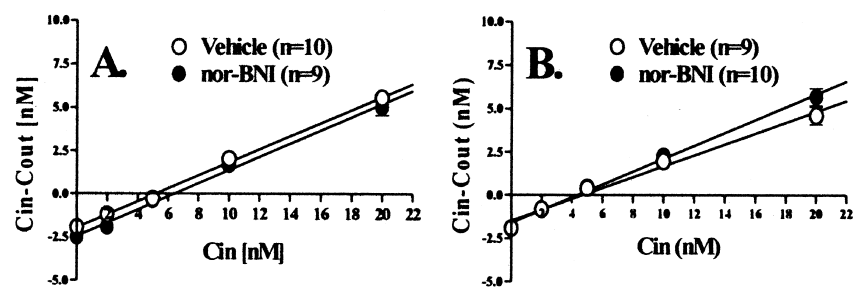

Figure 6. Influence of acute or prolonged KOR-1 blockade on basal NAC DA dynamics. DA dynamics were quantified $1 \mathrm{~h}(\boldsymbol{A})$ and $24 \mathrm{~h}(\boldsymbol{B})$ after pretreatment with nor-BNI. $\boldsymbol{A}, \boldsymbol{B}$, Plots of the average gain or loss of $\mathrm{DA}\left(C_{\text {in }}-C_{\text {out }}\right)$ to or from perfusate and the average linear regression fit of the data from no-net-flux microdialysis for each experimental group. The slope of the regression line represents the $E_{\mathrm{d}}$. The point when no DA is gained or lost from the perfusate $\left(C_{\text {in }}-\right.$ $C_{\text {out }}=0$ ) represents an unbiased estimate of $D A_{\text {ext }}$ concentration.

$\left.F_{(1,52)}=3.59 ; p=0.06\right)$, and a significant challenge $\times$ pretreatment interaction $\left(F_{(1,52)}=4.85 ; p=0.03\right)$. Analysis of simple effects revealed a significant effect of pretreatment in cocainechallenged animals $\left(F_{(1,25)}=4.86 ; p=0.037\right)$. These results indicate that cocaine challenge significantly increased DA levels in both pretreatment groups but that the magnitude of this effect was greater in nor-BNI pretreated mice. Analysis of cocaineinduced locomotor activity revealed significant effects of cocaine challenge $\left(F_{(1,37)}=54.47 ; p<0.001\right)$ and nor-BNI pretreatment $\left(F_{(1,37)}=4.12 ; p=0.05\right)$. However, the challenge $\times$ pretreatment interaction did not attain statistical significance $\left(F_{(1,37)}=3.92\right.$; $p=0.056)$. These findings indicate that nor-BNI treatment resulted in an enhanced behavioral response to cocaine as well as saline.

\section{Discussion}

Constitutive KOR-1 deletion increased basal DA dynamics in the NAc and enhanced cocaine-evoked DA overflow in this brain region. The locomotor activating effects of cocaine were en- 
A.

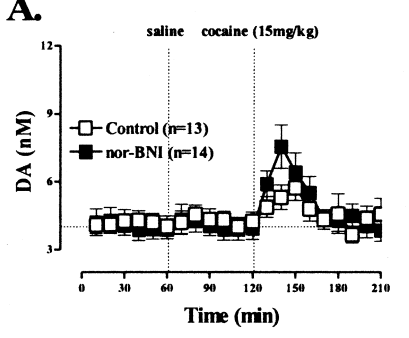

B.

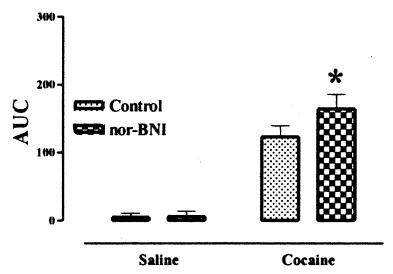

C.

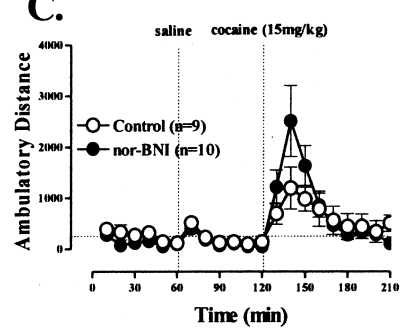

D.

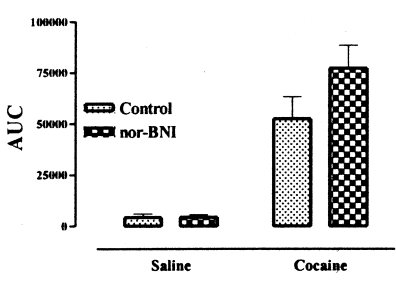

Figure 7. DA levels in the NAc and locomotor activity response to an acute cocaine challenge. $\boldsymbol{A}$, Time course of dialysate DA levels in the NAc in control (open squares) and nor-BNI-treated (filled squares) animals. Each point represents the mean \pm SEM; $n$ indicates the number of animals per experimental group. Abscissa, Microdialysis fractions ( $10 \mathrm{~min}$ ) before and after ( 0.1 $\mathrm{ml} / 10 \mathrm{~g}$, i.p.) saline and cocaine ( $15 \mathrm{mg} / \mathrm{kg}$, i.p.) injections. Vertical dotted lines represent the time of saline and cocaine injections. $\boldsymbol{B}$, AUC values for cocaine-evoked DA dialysate levels expressed as means \pm SEM. ${ }^{*}$ denotes significant difference between control and nor-BNItreated animals. $\boldsymbol{C}$, The time course of locomotor activity before and after cocaine challenge in control (open circles) and nor-BNI-treated (filled circles) animals. Each point represents the mean \pm SEM; $n$ indicates the number of animals per experimental group. Ordinate, Ambulatory distance. Abscissa, Time (minutes). Vertical dotted lines represent the time of saline and cocaine injections. D, AUC values for cocaine-evoked locomotor activity expressed as means $\pm S E M$. * denotes significant difference between control and nor-BNI-treated animals.

hanced, whereas the ability of cocaine to induce IEG expression was reduced. Studies using the long-acting KOR-1 antagonist nor-BNI revealed that the behavioral and neurochemical responses to cocaine were also enhanced in WT mice after prolonged ( $24 \mathrm{~h}$ ) KOR-1 blockade. Analogous to KO mice, basal DA uptake was increased, whereas $\mathrm{DA}_{\text {ext }}$ was unaltered. In contrast, after only $1 \mathrm{~h}$ blockade, $\mathrm{DA}_{\text {ext }}$ was elevated, but DA uptake was unchanged.

Intra-NAc infusion of U-69,593 decreased dialysate DA levels in the NAc of WT mice, confirming that the activation of NAc KOR receptors is sufficient to decrease mesoaccumbal DA neurotransmission (Spanagel et al., 1992). No alteration in dialysate DA levels was observed in KOR-1 KO mice. These findings indicate that the inhibitory effects of KOR agonists result from the specific activation of KOR-1 receptors and that this receptor is absent in KO mice. Furthermore, the demonstration that basal dialysate DA levels are elevated in these animals provides genetic evidence for the existence of a tonically active KOR-1 system that inhibits the activity of DA neurons projecting to the NAc.

Increased dialysate levels of DA may reflect increased release, decreased uptake, or their combination (Justice, 1993). Quantitative microdialysis studies permitted identification of the specific alterations in basal DA dynamics that result from KOR-1 deletion. In contrast to dialysate DA levels, $\mathrm{DA}_{\mathrm{ext}}$ was unchanged in the NAc of mutant mice, whereas basal DA uptake was increased. The lack of change in $\mathrm{DA}_{\text {ext }}$, despite the change in uptake, indicates that basal DA release is enhanced in the absence of KOR-1. It further suggests that endogenous KOR-1 systems decrease presynaptic DA neurotransmission via inhibition of release.

DAT protein levels were unaltered in KO mice. However, the $K_{\mathrm{m}}$ of DA uptake in the NAc was decreased. A previous study showed that the rate of DA clearance in NAc is altered in response to acute or repeated administration of KOR-1 agonists (Thompson et al., 2000). Although the mechanisms by which KOR-1 regulates DAT function is unclear, KOR-1 is colocalized with DAT on NAc DA axon terminals, providing an anatomical basis for the interaction of these proteins (Svingos et al., 2001). Therefore, the alteration in uptake may result from loss of KOR-1 that regulates DAT function. Interestingly, coimmunoprecipitation of KOR-1 and DAT has been described in heterologous expression systems (Bolan et al., 2004). The absence of KOR-1 signaling may, thus, induce a conformational change in DAT that increases uptake affinity. In view, however, of the effects of nor-BNI in WT mice (see below), it appears more likely that the increased uptake is an adaptation to the mutation that attempts to maintain homeostasis in the presence of increased DA release.

Systemic administration of the selective KOR-1 antagonist nor-BNI results in a long-lasting blockade of KOR-1 (Broadbear et al., 1994). Studies assessing the influence of this antagonist on basal DA dynamics in WT mice strongly suggest that the increased DA uptake in KO mice is not merely a developmental compensation resulting from constitutive gene deletion. Rather, it is a neuroplastic response that occurs because of disinhibition of mesoaccumbal DA neurons and the resulting increase in DA release. $\mathrm{DA}_{\text {ext }}$ was increased, whereas $E_{\mathrm{d}}$ was unchanged $1 \mathrm{~h}$ after nor-BNI administration. Because $\mathrm{DA}_{\text {ext }}$ is determined by both release and uptake, these data suggest that basal DA release is increased after acute KOR-1 inactivation. When, however, KOR-1 was inactivated for $24 \mathrm{~h}, \mathrm{DA}_{\text {ext }}$ was unaltered but $E_{\mathrm{d}}$ was increased. These findings indicate that DA uptake and release are enhanced after prolonged KOR-1 inactivation. A similar increase in uptake and release was observed in $\mathrm{KO}$ mice. Together, these data suggest that the absence of a KOR-1-mediated inhibition of mesoaccumbal DA neurotransmission triggers short- and longterm adaptations of DAT, which maintain normal DA $\mathrm{ext}_{\text {in }}$ the face of enhanced release.

Acute cocaine administration increases dialysate DA levels in the NAc by binding to DAT and inhibiting DA reuptake (Kuhar et al., 1991). Experimenter-administered cocaine as well as cocaine self-administration induce prodynorphin gene expression in the dorsal striatum (Spangler et al., 1993) and, to a lesser extent, the NAc (Turchan et al., 1998). Dynorphin tissue levels are also increased (Hanson et al., 1995). Given the inhibitory effect of KOR-1 agonists on DA neurotransmission, it has been suggested that cocaine increases the activity of KOR-1 systems, and this increase opposes the behavioral and DA responses to cocaine that develop after its repeated use (Shippenberg et al., 2001; Kreek et al., 2002; Shippenberg and Chefer, 2003). To date, a direct test of this hypothesis has been lacking.

KOR-1 KO mice exhibited an increase in the locomotor activating effects of cocaine relative to WT. The ability of cocaine to increase NAc dialysate DA levels was also enhanced. These findings indicate an important role of KOR-1 in modulating responsiveness to cocaine. Furthermore, they suggest that induction of prodynorphin is an adaptive response that attenuates the effects of acute cocaine administration. Interestingly, repeated intermittent administration of cocaine to WT mice resulted in an enhancement of its locomotor activating effects, consistent with the development of behavioral sensitization. No additional enhancement of behavior occurred in $\mathrm{KO}$ mice. Furthermore, the magnitude of locomotor activation that occurred in $\mathrm{KO}$ mice after acute cocaine injection equaled that of WT mice that had received 
cocaine repeatedly. These data indicate that, in the absence of KOR-1, animals are in a chronically sensitized state. Because of this state, repeated cocaine administration is ineffective in further enhancing behavior.

Behavioral sensitization once developed is progressive and long lasting (Kalivas and Duffy, 1993). An enhanced response is apparent 1-2 d after the cessation of repeated cocaine administration and increases as abstinence proceeds. In contrast, prodynorphin gene expression is elevated during the early phase of cocaine abstinence and then decreases (Svensson and Hurd, 1998). These data and those of the present study are consistent with the hypothesis that increased KOR-1 activity during early abstinence limits the development of sensitization. As abstinence progresses and the activity of KOR-1 systems decreases, an additional enhancement of cocaine-evoked behavioral is seen.

Acute cocaine administration induces the expression of a number of IEGs in the NAc and other brain regions. In striatum, both the regional and temporal patterns of c-fos induction after acute cocaine treatment are inversely related to those of prodynorphin. In contrast to the IEG induction produced by acute cocaine, treatment regimens that result in behavioral sensitization result in a blunted IEG response (Hope et al., 1992; Zhang et al., 2002). Acute cocaine administration increased brain c-fos, jun $\mathrm{B}$, and fos $\mathrm{B}$ expression in WT mice. However, analogous to that observed in the NAc of animals exhibiting behavioral sensitization, acute cocaine administration produced a blunted IEG response in mutant mice. These findings provide additional evidence that loss of KOR-1 results in a "cocaine-sensitized" phenotype.

The ability of cocaine and other drugs of abuse to increase NAc DA levels has been implicated in the rewarding effects of these agents and the initiation of drug abuse (Wise and Bozarth, 1987). The increase in cocaine-evoked DA levels observed in KO and nor-BNI-treated WT mice suggests that decreased activity of KOR-1 systems may be associated with greater vulnerability to cocaine abuse. The transition, however, from drug abuse to the compulsive drug seeking that characterizes addiction has been attributed to neuroadaptations that occur as a consequence of repeated drug use. It has been hypothesized that the processes underlying behavioral sensitization contribute, at least in part, to the initiation and reinstatement of compulsive drug use (Cornish and Kalivas, 2001; Robinson and Berridge, 2001, 2003). Consistent with this hypothesis, the propensity to develop psychostimulant self-administration is correlated with the development of conditioned hyperlocomotion and environment-specific sensitization (Jodogne et al., 1994). Furthermore, the initiation and reinstatement of compulsive drug seeking is correlated with the magnitude of the sensitized locomotor response that develops to psychostimulants (De Vries et al., 1998; Vezina, 2004). To the extent that similar processes contribute to the development of sensitization and compulsive drug seeking, then individuals with KOR-1 hypofunction may be at greater risk for developing cocaine addiction. Importantly, however, although KO mice exhibited an augmented behavioral response to acute cocaine, they did not exhibit an additional enhancement of cocaine-evoked behavior in response to repeated administration. Therefore, if, in fact, the progressive enhancement of cocaine-evoked behavior that occurs with repeated use leads to compulsive drug seeking, then individuals with diminished KOR-1 function may exhibit a reduced propensity to develop compulsive cocaine seeking.

In conclusion, the present studies demonstrate a critical role of endogenous KOR-1 systems in regulating the activity of mesoaccumbal DA neurons. Loss of this system is associated with increased basal DA release and a progressive increase in DAT function that opposes the increase in release and normalizes $\mathrm{DA}_{\text {ext }}$. Gene ablation and pharmacological inactivation of KOR-1 resulted in an enhancement of the behavioral and neurochemical effects of cocaine, providing the first direct evidence that KOR-1 systems function as endogenous antagonists of cocaine.

\section{References}

Bolan EA, Shan LF, Devi LA, Javitch JA, Thompson AC, Chefer VI, Shippenberg TS (2004) Regulation of dopamine transporter function by $\kappa$-opioid receptors: role of protein trafficking. Soc Neurosci Abstr 30:280.11.

Broadbear JH, Negus SS, Butelman ER, de Costa BR, Woods JH (1994) Differential effects of systemically administered nor-binaltorphimine (norBNI) on kappa-opioid agonists in the mouse writhing assay. Psychopharmacology (Berl) 115:311-319.

Cornish JL, Kalivas PW (2001) Cocaine sensitization and craving: differing roles for dopamine and glutamate in the nucleus accumbens. J Addict Dis 20:43-54.

Daunais JB, Roberts DC, McGinty JF (1993) Cocaine self-administration increases preprodynorphin, but not c-fos, mRNA in rat striatum. NeuroReport 4:543-546.

De Vries TJ, Schoffelmeer AN, Binnekade R, Mulder AH, Vanderschuren LJ (1998) Drug-induced reinstatement of heroin- and cocaine-seeking behaviour following long-term extinction is associated with expression of behavioural sensitization. Eur J Neurosci 10:3565-3571.

Gibaldi M, Perier D (1975) The trapezoid rule. In: Pharmacokinetics (Gibaldi M, Perier D, eds), pp 293-296. New York: Dekker.

Hanson GR, Singh N, Merchant K, Johnson M, Gibb JW (1995) The role of NMDA receptor systems in neuropeptide responses to stimulants of abuse. Drug Alcohol Depend 37:107-110.

Heidbreder CA, Shippenberg TS (1994) U-69593 prevents cocaine sensitization by normalizing basal accumbens dopamine. NeuroReport 5:1797-1800.

Heijna MH, Padt M, Hogenboom F, Portoghese PS, Mulder AH, Schoffelmeer AN (1990) Opioid receptor-mediated inhibition of dopamine and acetylcholine release from slices of rat nucleus accumbens, olfactory tubercle and frontal cortex. Eur J Pharmacol 181:267-278.

Hope B, Kosofsky B, Hyman SE, Nestler EJ (1992) Regulation of immediate early gene expression and AP-1 binding in the rat nucleus accumbens by chronic cocaine. Proc Natl Acad Sci USA 89:5764-5768.

Hough LB, Nalwalk JW, Chen Y, Schuller A, Zhu Y, Zhang J, Menge WM, Leurs R, Timmerman H, Pintar JE (2000) Improgan, a cimetidine ana$\log$, induces morphine-like antinociception in opioid receptor-knockout mice. Brain Res 880:102-108.

Jodogne C, Marinelli M, Le Moal M, Piazza PV (1994) Animals predisposed to develop amphetamine self-administration show higher susceptibility to develop contextual conditioning of both amphetamine-induced hyperlocomotion and sensitization. Brain Res 657:236-244.

Justice JBJ (1993) Quantitative microdialysis of neurotransmitters. J Neurosci Methods 48:263-276.

Kalivas PW, Duffy P (1993) Time course of extracellular dopamine and behavioral sensitization to cocaine. I. Dopamine axon terminals. J Neurosci 13:266-275.

Kreek MJ, LaForge KS, Butelman E (2002) Pharmacotherapy of addictions. Nat Rev Drug Discov 1:710-726.

Kuhar MJ, Ritz MC, Boja JW (1991) The dopamine hypothesis of the reinforcing properties of cocaine. Trends Neurosci 14:299-302.

Mansour A, Fox CA, Akil H, Watson SJ (1995) Opioid-receptor mRNA expression in the rat CNS: anatomical and functional implications. Trends Neurosci 18:22-29.

Parsons LH, Smith AD, Justice JBJ (1991a) Basal extracellular dopamine is decreased in the rat nucleus accumbens during abstinence from chronic cocaine. Synapse 9:60-65.

Parsons LH, Smith AD, Justice JBJ (1991b) The in vivo microdialysis recovery of dopamine is altered independently of basal level by 6-hydroxydopamine lesions to the nucleus accumbens. J Neurosci Methods 40:139-147.

Robinson TE, Berridge KC (2001) Incentive-sensitization and addiction. Addiction 96:103-114.

Robinson TE, Berridge KC (2003) Addiction. Annu Rev Psychol 54:25-53. Schenk S, Partridge B, Shippenberg TS (1999) U69593, a kappa-opioid ag- 
onist, decreases cocaine self-administration and decreases cocaineproduced drug-seeking. Psychopharmacology (Berl) 144:339-346.

Shippenberg TS, Chefer VI (2003) Opioid modulation of psychomotor stimulant effects. In: Molecular biology of drug addiction (Maldonado R, ed), pp 107-132. Totowa, NJ: Humana.

Shippenberg TS, He M, Chefer V (1999) The use of microdialysis in the mouse: conventional versus quantitative techniques. Psychopharmacology (Berl) 147:33-34.

Shippenberg TS, Chefer VI, Zapata A, Heidbreder CA (2001) Modulation of the behavioral and neurochemical effects of psychostimulants by kappaopioid receptor systems. Ann NY Acad Sci 937:50-73.

Slotnick BM, Leonard CM (1975) A stereotaxic atlas of the albino mouse forebrain, p 174. Rockville, MD: US Department of Health, Education, and Welfare.

Smith AD, Justice JB (1994) The effect of inhibition of synthesis, release, metabolism and uptake on the microdialysis extraction fraction of dopamine. J Neurosci Methods 54:75-82.

Spanagel R, Herz A, Shippenberg TS (1992) Opposing tonically active endogenous opioid systems modulate the mesolimbic dopaminergic pathway. Proc Natl Acad Sci USA 89:2046-2050.

Spangler R, Unterwald EM, Kreek MJ (1993) "Binge" cocaine administration induces a sustained increase of prodynorphin mRNA in rat caudateputamen. Brain Res Mol Brain Res 19:323-327.

Steiner H, Gerfen CR (1995) Dynorphin opioid inhibition of cocaine- induced, D1 dopamine receptor-mediated immediate-early gene expression in the striatum. J Comp Neurol 353:200-212.

Svensson P, Hurd YL (1998) Specific reductions of striatal prodynorphin and D1 dopamine receptor messenger RNAs during cocaine abstinence. Brain Res Mol Brain Res 56:162-168.

Svingos AL, Chavkin C, Colago EE, Pickel VM (2001) Major coexpression of kappa-opioid receptors and the dopamine transporter in nucleus accumbens axonal profiles. Synapse 42:185-192.

Thompson AC, Zapata A, Justice JB, Vaughan RA, Sharpe LG, Shippenberg TS (2000) $\kappa$-Opioid receptor activation modifies dopamine uptake in the nucleus accumbens and opposes the effects of cocaine. J Neurosci 20:9333-9340.

Turchan J, Przewlocka B, Lason W, Przewlocki R (1998) Effects of repeated psychostimulant administration on the prodynorphin system activity and kappa opioid receptor density in the rat brain. Neuroscience 85:1051-1059.

Vezina P (2004) Sensitization of midbrain dopamine neuron reactivity and the self-administration of psychomotor stimulant drugs. Neurosci Biobehav Rev 27:827-839.

Wise RA, Bozarth MA (1987) A psychomotor stimulant theory of addiction. Psychol Rev 94:469-492.

Zhang D, Zhang L, Lou DW, Nakabeppu Y, Zhang J, Xu M (2002) The dopamine D1 receptor is a critical mediator for cocaine-induced gene expression. J Neurochem 82:1453-1464. 